\title{
Dynamic Behavior of Rapeseed Oil Spray in Diesel Engine
}

\author{
Azwan Sapit ${ }^{1, a}$, Mohd Azahari Razali, ${ }^{1, b}$, Mohd Faisal Hushim ${ }^{1, c}$, \\ M. Jaat ${ }^{1, \mathrm{~d}}$, Akmal Nizam Mohammad ${ }^{1, \mathrm{e}}$ and Amir Khalid ${ }^{1, \mathrm{f}}$
}

\author{
${ }^{1}$ Automotive Research Group, Faculty of Mechanical and Manufacturing Engineering, \\ Universiti Tun Hussein Onn Malaysia, Parit Raja, 86400 Batu Pahat, Johor, Malaysia. \\ aazwans@uthm.edu.my, bazahari@uthm.edu.my, 'mdfaisal@uthm.edu.my \\ dnorrizam@uthm.edu.my, ${ }^{e}$ akmaln@uthm.edu.my, ${ }^{f}$ amirk@uthm.edu.my
}

\section{Keywords: Diesel Engine Spray, Rapeseed Oil, Biomass Fuel, Atomization, Droplets Dynamic}

\begin{abstract}
Fuel-air mixing is important process in diesel combustion which significantly affects the combustion and emission of diesel engine. Due to the nature of biomass fuel that has high viscosity and high distillation temperature, the condition and furthermore the improvement of atomization process is very important. This study investigates the atomization characteristics and droplet dynamic behaviors of diesel engine spray fueled by rapeseed oil (RO). Optical observation of RO spray was carried out using shadowgraph photography technique. Single nano-spark photography technique was used to study the characteristics of the rapeseed oil spray while dual nano-spark shadowgraph technique was used to study the spray droplet behavior. Using in-house image processing algorithm, the images were processed and the boundary condition of RO spray also was studied. The results show that RO has very poor atomization due to the high viscosity nature of the fuel. This is in agreement with the results from spray droplet dynamic behavior studies that shows due to the high viscosity, the droplets are large in size and travel downward, with very little influence of entrainment effect due to its large kinematic energy.
\end{abstract}

\section{Introduction}

Study on diesel engine shows fuel that derived from biomass such as a vegetable oil fuel is a viable alternative to current fossil fuel [1]. However studies show that, when diesel engines use neat biomass fuel, NOx emissions increase [2]. Particulate emissions decreases at heavy load due to oxygenated nature of biomass fuel; in contrast, SOF (Soluble organic fraction) emissions increases at light load operation [3]. These kinds of emission formation are greatly affected by spray atomization. Precise optimization of the fuel injection, spray atomization and fuel-air mixing are among the fundamental factors that control the combustion and emission formation[4-5]. Application of high-pressure injection and high ambient temperature could promote better spray atomization and fuel-air mixing, and this should be applicable to biomass fuel too. There are also studies which suggest the geometry of piston cavity design can improve mixture formation and emission level. Generally, biomass fuel is subjected to transesterification process to improve biomass fuel combustion and prevent carbon buildup during engine combustion[6]. However, it is still desirable to use neat biomass fuel without transesterification, especially when the technology to process biomass fuel to biodiesel is not accessible (rural area) and when considering cost. Thus, it is important to firstly understand the spray characteristics of biomass fuel, which is the objective of this study by the means of optical technique. In addition, by using the same technique fitted with dual nano-spark shadowgraph optical arrangement, rapeseed oil spray droplet behavior can be studied.

\section{Experiment Setup}

Figure 1 shows the experimental setup of shadowgraph photography. The experimental system is the same as previous work [7]. It is composed of spray chamber, rapid compression machine (RCM), fuel injection device and optical system. A rapid compression machine was used to create diesel atmosphere in the spray chamber. The spray chamber has two quartz windows in diameter of $60 \mathrm{~mm}$ for the access of nano-spark light [7] to a still camera. The spray chamber was filled with inert gas 
mixture of nitrogen and argon to prevent spray ignition. When ambient temperature reaches designated temperature after termination of rapid compression, fuel was injected into the spray chamber and spray behavior was taken by the optical system. Figure 2 shows the dual nano-spark optical arrangement [7] which can take simultaneously two pictures with little time interval of the same spray. All the images taken by films were scanned and changed to digital pictures. Then using in house algorithm system developed by Yatsufusa[8], the image is analyze and spray fuel droplet can be verified.

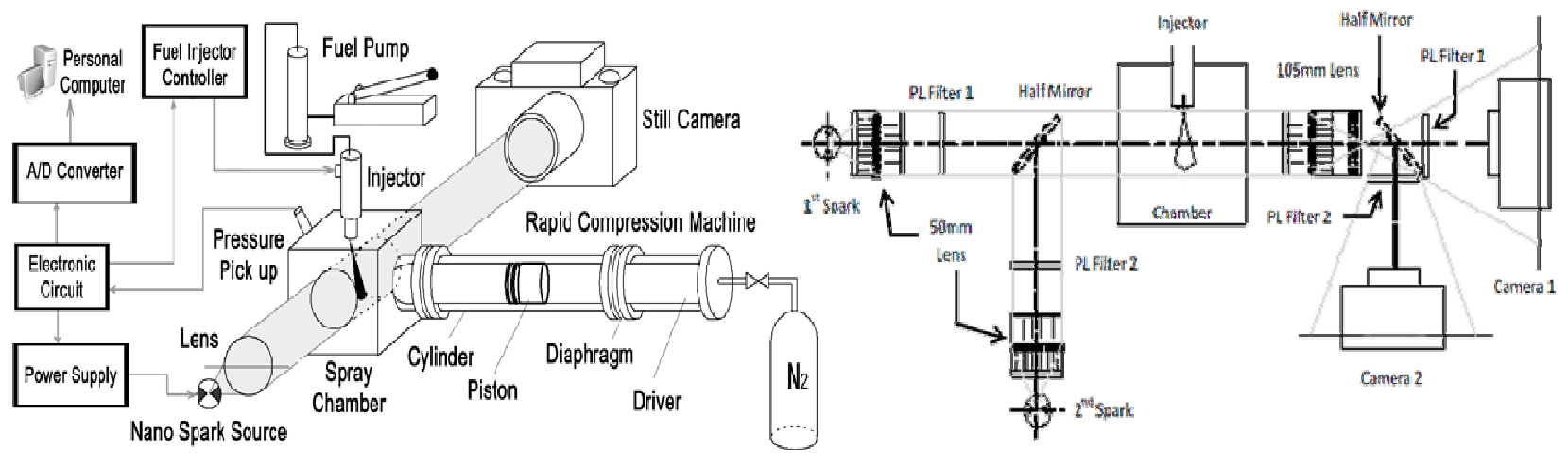

Fig. 1 Spray observation system and optical arrangement for single nano-spark shadowgraph photography method

Fig.2 Optical arrangement for dual nano-spark shadowgraph photography technique

Fuels used were rapeseed oil (RO) and JIS\#2 diesel fuel or gas oil (GO). The kinematic viscosity of RO is $47.78 \mathrm{~mm}^{2} / \mathrm{st} @ 303 \mathrm{~K}$ (density $911 \mathrm{~kg} / \mathrm{m}^{3}$ ) and GO $3.30 \mathrm{~mm} / \mathrm{st} @ 303 \mathrm{~K}\left(827 \mathrm{~kg} / \mathrm{m}^{3}\right)$. The $50 \%$ distillation temperatures of $\mathrm{RO}$ and $\mathrm{GO}$ are about $880 \mathrm{~K}$ and $570 \mathrm{~K}$, respectively .

\section{Result and Discussion}

Figure 3 shows GO spray image and its analysis at $\mathrm{T}_{\mathrm{i}}=298 \mathrm{~K}, \mathrm{P}_{\mathrm{inj}}=70 \mathrm{MPa}, \mathrm{t}=0.50 \mathrm{~ms}$ aSOI (after start of injection), taken by dual nano-spark shadowgraphy and time interval between nano-spark 1 to 2 is $\Delta t=25 \mu \mathrm{s}$. Figure 3 (a) shows the original images, (b) shows the droplet vector calculated by comparing the image from camera 1 to camera 2, (c) shows the averaged droplet flying velocity and (d) shows the averaged droplet flying angle. Figure 3 (b) y axis shows the spray travel distance with $Z_{\mathrm{sp}}=0$ equal to nozzle tip. The analysis first divides spray length into 4 sections, $0-25 \%$ (upper), $25-50 \%$ (middle), $50-75 \%$ (lower) and $75-100 \%$ (tip) of spray length for notation purpose. In fig.3(c) and (d), for $Z_{\mathrm{sp}}=0$ to $60 \mathrm{~mm}$, each $10 \mathrm{~mm}$ is divided into individual sections, with the averaged value is calculated for each section. The flying angle is considered to be $0^{\circ}$ along the $\mathrm{x}$ axis, with positive value clock-wise. Error bar shows the standard deviation.

From the vector line shown in Fig.3(b), it can be seen that the droplets in the middle and lower section of the spray moving outward from the spray boundary, meanwhile the droplets in the upper section is moving inside toward the spray body. This can be confirmed by observing the droplet flying angle graph in Fig.3(d), as the section of $Z_{\mathrm{sp}}=0 \sim 20 \mathrm{~mm}$ shows negative value. Droplets of the upper section, which subjected to atomization for a longer duration, has smaller diameter and easier to be influence by air entrainment due to small kinetic energy compared to droplets of the medium and lower section. This made the upper section droplets seem to be sucked into, or entrained into the spray body. In comparison, the middle and lower section droplets formed after the formation of spray body thus having a bigger kinetic energy fly outward

Figure 4 shows RO spray image and its analysis at $\mathrm{T}_{\mathrm{i}}=298 \mathrm{~K}, \mathrm{P}_{\text {inj }}=70 \mathrm{MPa}, \mathrm{t}=0.50 \mathrm{~ms}$ aSOI (after start of injection) taken by dual nano-spark shadowgraphy and time interval between nano-spark 1 to 2 is $\Delta \mathrm{t}=25 \mu \mathrm{s}$, similar to Fig. 3. It can be observed from Fig.4(b), droplets vector in the upper section especially at $Z_{\mathrm{sp}}=0 \sim 20 \mathrm{~mm}$ is small, similar to that of the GO. Air entrainment influence also can be seen as the droplets are moving toward the spray body. By observing the section of $Z_{\mathrm{sp}}=0 \sim 20 \mathrm{~mm}$ of Fig.4(c) and (d), which has similar value to GO, it is understood that the RO spray upper section droplets dynamic is similar to GO. 
In contrast, at $Z_{\mathrm{sp}}=20 \sim 40 \mathrm{~mm}$, the droplets move along the spray axis, with smaller entrainment effect. The same tendency can be observed when $Z_{\mathrm{sp}}=40 \mathrm{~mm}$ and larger. This flying angle tendency of RO spray droplets at middle and lower section is different from GO. Difference in droplet size, with the larger droplets of RO have bigger kinetic energy and the not easily affected by air entrainment. This made the droplets move along the spray axis with little deviation and believed to the one of the reason that made RO spray cone angle smaller when compared to GO.

Fuel droplets on the spray tip is continuously under surrounding gas aerodynamic forces, decreasing its velocity, and at the same time, the droplets that came after that pushes forward and replace the existing droplets on the spray tip. The droplets with low kinetic energy are pushed aside and form the outer spray region. This mechanism can be seen on the GO and RO spray. RO spray has high viscosity which made the droplets (quantity) that were pushed aside due to aerodynamic forces was small in numbers. This in turn made the spray cone angle smaller than of the GO and also the branching structure was not well developed. The final result is poor atomization for RO spray. In contrast, as the RO spray droplets kinetic energy is greater than of the GO, the spray penetration length is longer.

Figure 5 shows RO spray image and its analysis at $\mathrm{T}_{\mathrm{i}}=700 \mathrm{~K}, \mathrm{P}_{\mathrm{inj}}=70 \mathrm{MPa}, \mathrm{t}=0.50 \mathrm{~ms}$ aSOI and time interval between nano-spark 1 to 2 is $\Delta \mathrm{t}=25 \mu \mathrm{s}$, similar to Fig.4. The high ambient temperature decrease RO spray viscosity and this can be confirmed with the increase of spray cone angle. In addition when compared to Fig.4(b) at $\mathrm{T}_{\mathrm{i}}=298 \mathrm{~K}$ where air entrainment effect can be clearly seen especially at the middle and lower section, it can be observed that droplets fly inward to the spray body exhibiting the influence of air entrainment. Figure 5(c) and (d) shows that the droplets velocity vector becomes small and at the lower section can be seen to fly outward of spray body. Decrease in the droplets size due to lower viscosity of RO spray is believed to be the reasons of these results. Based on these findings, it is clear that high ambient temperature improves atomization of RO spray.
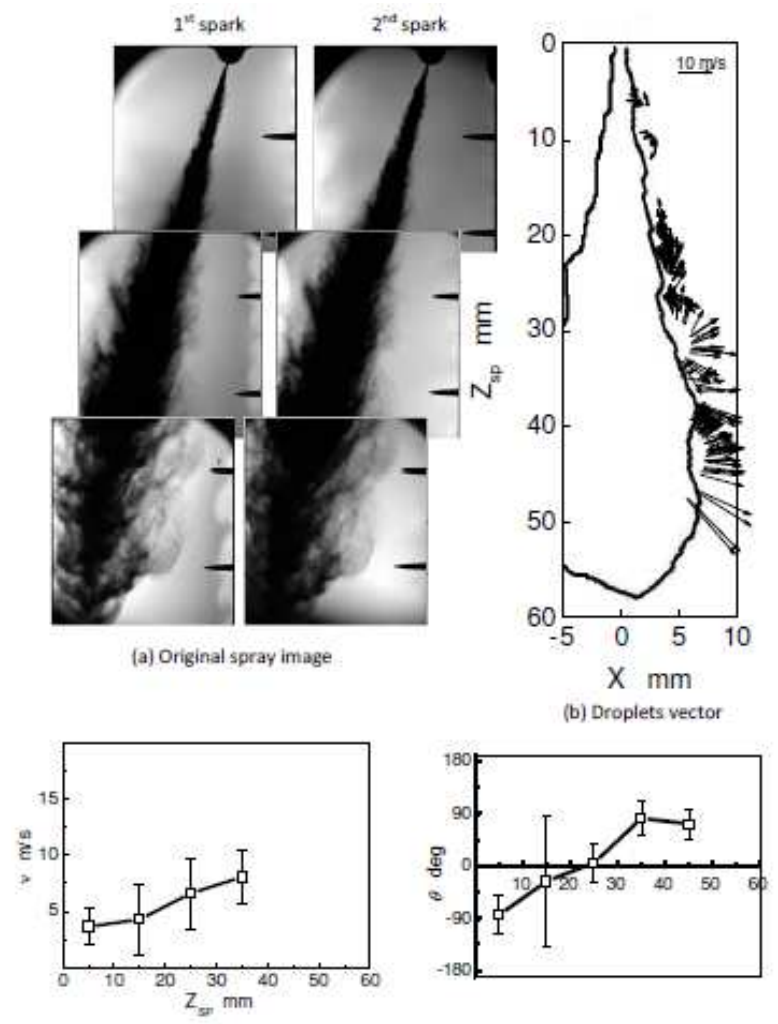

(c) Droplets flying velocity

(d) Droplets flying angle

Fig. 3 Gas oil spray images and droplets behavior $\left(\mathrm{T}_{\mathrm{i}}=298 \mathrm{~K}, \mathrm{P}_{\mathrm{inj}}=70 \mathrm{MPa}, \mathrm{t}=0.50 \mathrm{~ms}\right)$ 


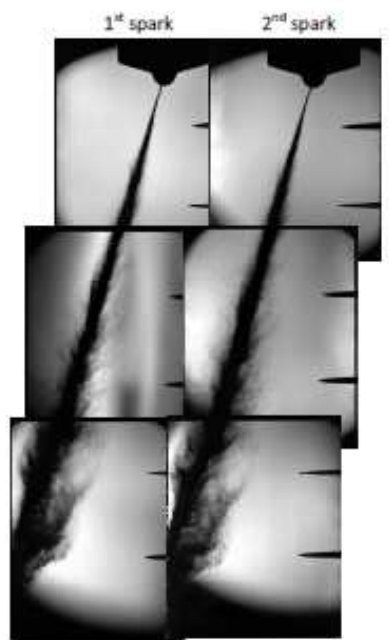

(a) Original spray image

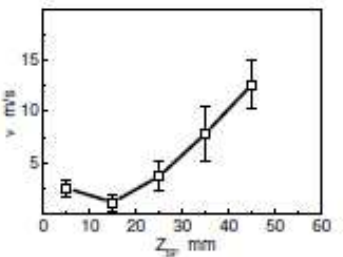

(c) Droplets flying velocity

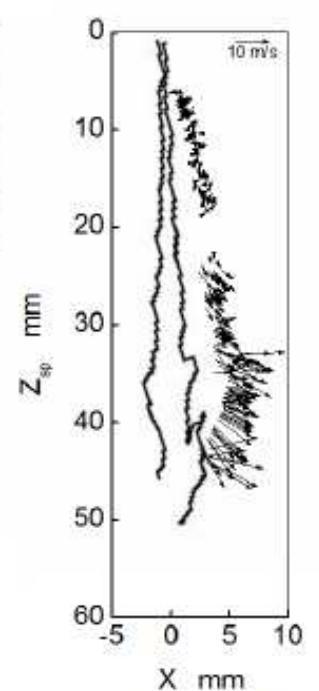

(b) Droplets vector

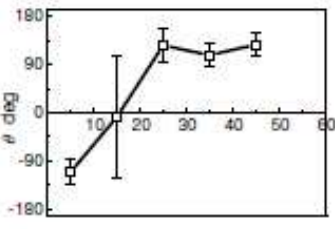

(d) Droplets flying angle

Fig.4 Rapeseed oil spray images and droplets behavior $\left(\mathrm{T}_{\mathrm{i}}=298 \mathrm{~K}, \mathrm{P}_{\mathrm{ini}}=70 \mathrm{MPa}, \mathrm{t}=0.50 \mathrm{~ms}, \Delta \mathrm{t}=25 \mu \mathrm{s}\right)$

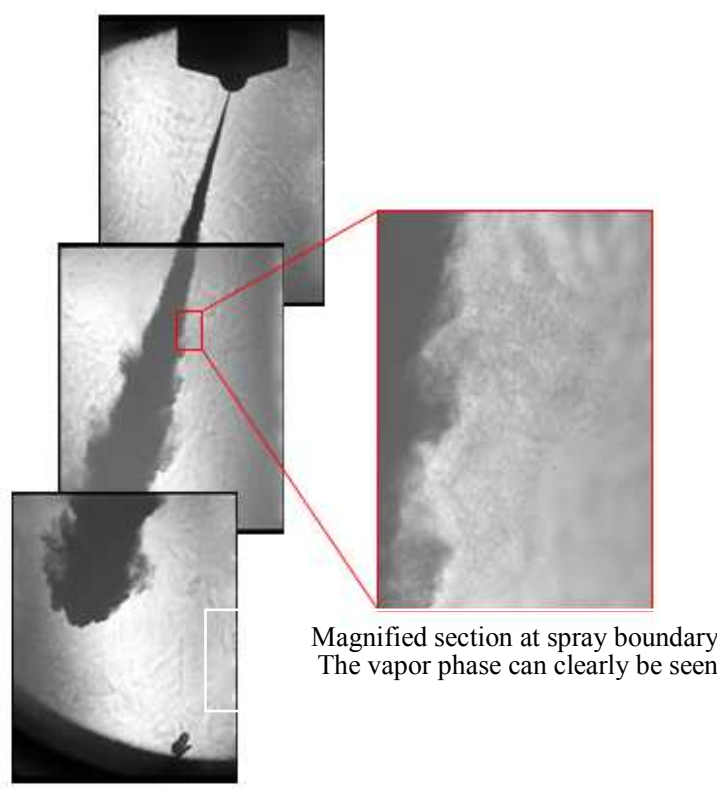

Fig.6. Vaporization of rapeseed oil spray $\left(\mathrm{T}_{\mathrm{i}}=850 \mathrm{~K}\right.$, $\mathrm{P}_{\mathrm{inj}}=70 \mathrm{MPa}, \mathrm{t}=0.50 \mathrm{~ms}$ )

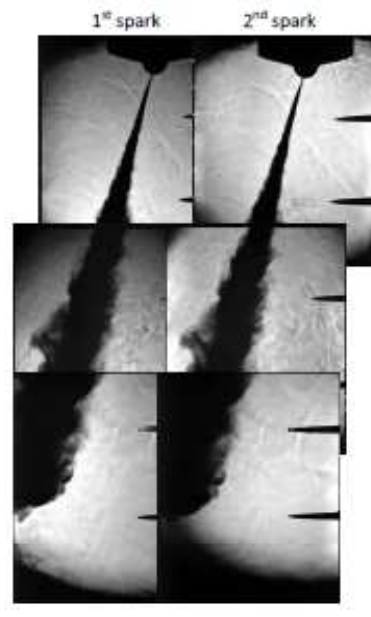

(a) Original spray image

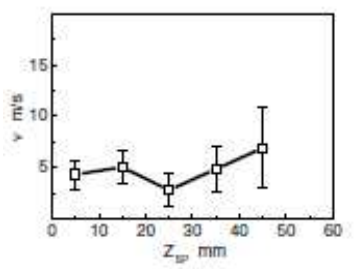

(c) Droplets flying velocity

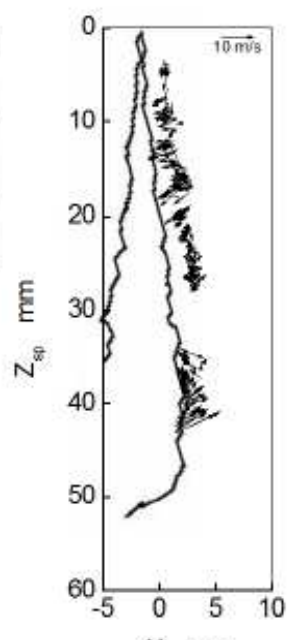

$\mathrm{X} \mathrm{mm}$

(b) Droplets vector

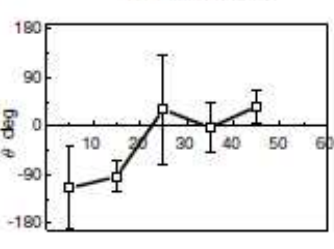

(d) Droplets flying angle

Fig.5 Rapeseed oil spray images and droplets behavior $\left(\mathrm{T}_{\mathrm{i}}=700 \mathrm{~K}, \mathrm{P}_{\text {ini }}=70 \mathrm{MPa}, \mathrm{t}=0.50 \mathrm{~ms}, \Delta \mathrm{t}=25 \mu \mathrm{s}\right)$

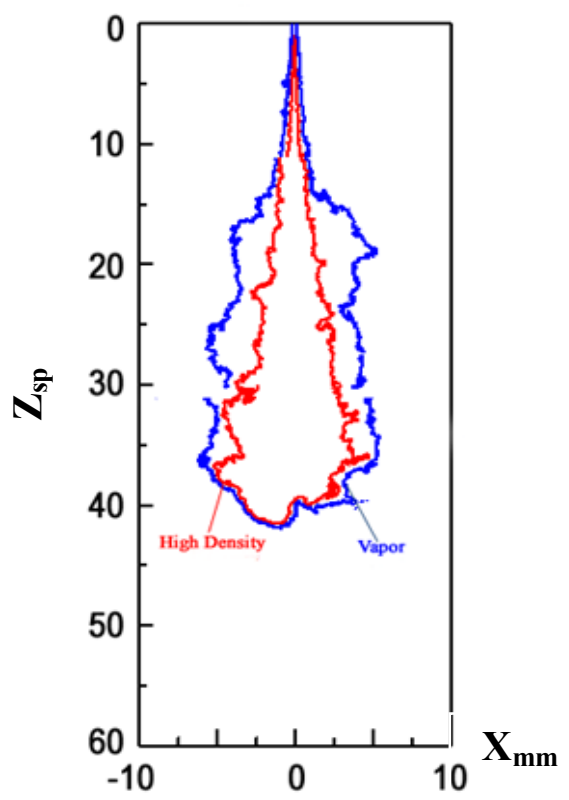

Fig.7 Boundary analysis of vaporization of rapeseed oil spray $\left(\mathrm{T}_{\mathrm{i}}=850 \mathrm{~K}, \mathrm{P}_{\mathrm{inj}}=70 \mathrm{MPa}, \mathrm{t}=0.50 \mathrm{~ms}\right)$

Fig. 6 show image of $\mathrm{RO}$ spray taken at $\mathrm{T}_{\mathrm{i}}=850 \mathrm{~K}, \mathrm{P}_{\mathrm{inj}}=70 \mathrm{MPa}, \mathrm{t}=0.50 \mathrm{~ms}$, with a magnified section located on the right side. The magnified image represents area from the full spray image marked with red boundary. From the magnified image it can be seen that at $\mathrm{T}_{\mathrm{i}}=850 \mathrm{~K}$, the formation of vapor phase at spray boundary can be observed. This is very interesting as it is known from previous work, even at $\mathrm{T}_{\mathrm{i}}=700 \mathrm{~K}$, vapor phase is difficult to be observed. This result shows that in the condition of very high ambient temperature, RO spray (middle and lower section) undergoes atomization which eventually leads to vaporization. 
Fig.7 shows the high density liquid and vapor phase analysis of the image by using in-house image processing algorithm. The high density liquid dictated by red line and the vapor phase by blue line. $\mathrm{Y}$ axis is the spray length and $\mathrm{X}$ axis is the spray cross section thickness. The result shows that large area of vapor phase in the middle section. In contrast, high density liquid phase can be observed advancing at the spray tip. It is believed that in order to promote faster vaporization at the spray tip section, higher ambient temperature is required.

\section{Summary}

Rapeseed oil (RO) has very poor atomization when compared to gas oil spray. This is in agreement with the results from spray droplet dynamic behavior studies that show due to the high viscosity, RO has larger droplets size with bigger kinematic energy and not easily influence by the air entrainment, especially at the lower section of the spray. High ambient temperature promotes RO spray to expands further from the center line and improve atomization. However, it should also be noted that even at $\mathrm{T}_{\mathrm{i}}=700 \mathrm{~K}$, evaporation of RO spray can little be seen, and vapor region almost cannot be detected. This characteristic poses a problem to engine with low ambient temperature and running at low load, as it can be the cause of SOF increase due to poor atomization of the RO fuel. Very high ambient temperature is needed to improve the atomization of $\mathrm{RO}$ as shown in the result at $\mathrm{T}_{\mathrm{i}}=850 \mathrm{~K}$. This also indicate that other methods beside of very high ambient temperature; which difficult to attain when running at low speed, are needed to improve the atomization process is a must when using RO.

\section{Acknowledgement}

The authors also would like to thank the Ministry of Higher Education Malaysia for supporting this research under the Exploratory Research Grant Scheme (ERGS) vot.E032.

\section{Reference}

[1] R. D. Misra and M. S. Murthy, "Straight vegetable oils usage in a compression ignition engine-A review", Renewable and Sustainable Energy Reviews, vol. 14, pp. 3005-3013, 2010.

[2] Nabi M. N., Shahadat M. M. Z., Rahman M. S. and Beg M. R. A., "Behavior of Diesel Combustion and Exhaust Emission with Neat Diesel Fuel and Diesel- Biodiesel Blends", SAE Paper, 2004-01-3034, 2004.

[3] W. Jazair, T. Harada, S. Kubo and Y. Kidoguchi, "Improvement of Emissions in a DI Diesel Engine Fuelled by Bio-diesel Fuel and Waste Cooking Oil”, SAE Paper 2007-01-2029, 2007.

[4] Amir Khalid, M.D. Anuar, Yusri Ishak, B. Manshoor, Azwan Sapit, Mutalib Leman, Izzuddin Zaman, "Emissions characteristics of small diesel engine fuelled by waste cooking oil", MATEC Web of Conferences, Volume 13, 2014, Article number 06006, DOI: $10.1051 /$ matecconf/20141306006.

[5] Amir Khalid, Keisuke Hayashi, Yoshiyuki Kidoguchi, Tomoaki Yatsufusa, "Effect of air entrainment and oxygen concentration on endothermic and heat recovery process of diesel ignition", (2011) SAE Technical Papers, DOI: 10.4271/2011-01-1834.

[6] Amir Khalid, N.Tamaldin, M. Jaat, M. F. M. Ali, B. Manshoor, Izzuddin Zaman, "Impacts of biodiesel storage duration on fuel properties and emissions", Procedia Engineering, volume 68, 2013, Pages 225 - 230, Elsevier, 2013, DOI: 10.1016/j.proeng.2013.12.172.

[7] A. Sapit, S. Nagayasu, Y. Tsuboi, Y. Nada, and Y. Kidoguchi, "A Study on Improvement of Diesel Spray Characteristics Fueled by Rape-seed Oil”, SAE Paper, 2011-32-0561, 2011.

[8] Yatsufusa T., Kidoguchi Y., Adbullah A., Gomi T., "Measurement of particle diameter in diesel spray by long-distance microscopic shadowgraph photography", Atomization, Vol.18, No.63, pp.2-9, 2009. 